\title{
Hepatitis B infection among Nigerian children admitted to a children's emergency room
}

\author{
*Ayebo E Sadoh ${ }^{1}$, Antoinette Ofili ${ }^{2}$
}

1. Department of Child Health, University of Benin Teaching Hospital Benin City, Nigeria

2. Department of Community Health, University of Benin Teaching Hospital, Benin City, Nigeria

\begin{abstract}
Background: Nigeria commenced her hepatitis B immunization programme in 2004 but there have been few evaluations of the programme in different parts of the country given the fact that prevalence in different regions of the country varies. The objective of this study was to determine the prevalence of $\mathrm{HBsAg}$ and the hepatitis B immunization status among children admitted to the children's emergency room (CHER) in Benin Teaching Hospital.

Methods: A descriptive cross-sectional study carried out in 150 consecutively recruited children aged 2 months to 15 years admitted to the CHER of the University of Benin Teaching Hospital. HBsAg was assayed for in blood.

Results: HBsAg seroprevalence was $13.9 \%$. Majority $(83 \%)$ of the children were age appropriately immunized for hepatitis B. Mean age at receipt of the birth dose of hepatitis B $(28.0 \pm 20.4$ days $)$ was significantly delayed $(p<0.0001)$. Mean age at completion of the schedule(110 \pm 18.6 days) was significantly delayed compared to the recommended age of 98 days $\mathrm{p}<0.0002)$. Age, sex and socioeconomic status were not significantly associated with being seropositive $(\mathrm{p}>0,05)$.

Conclusion: HBsAg seroprevalence was high despite high immunization coverage. Lack of timeliness in the receipt of the birth dose and in completion of the schedule may have contributed to the seeming lack of effectiveness of the immunization programme,
\end{abstract}

Key words: Hepatitis B, Nigerian children, Emergency Room

African Health Sciences 2014; 14(2):377-383

DOI: http://dx.doi.org/10.4314/ahs.v14i2.13

\section{Introduction}

Hepatitis B virus infection is a disease of global public health significance with about a third of the world population showing evidence of infection while about 350 million of these are chronically infected.[1,2] Its prevalence varies from one region to another resulting in different levels of endemicity.[1] Prevalence may change over time and with the introduction of effective strategies such as universal immunization.

Nigeria which is highly endemic for hepatitis B had included the hepatitis B vaccine in its schedule in 1995 but the vaccine only became widely available in 2004 . $[3,4]$ The Nigerian hepatitis B immunization schedule for infants prescribes the receipt of a birth dose, a second dose at six weeks and a third dose at 14 weeks of life.[3]

There are various methods of assessing the success of an immunization programme.

\section{*corresponding author: \\ Ayebo E Sadoh \\ Department of Child Health \\ University of Benin Teaching Hospital \\ Benin City, Nigeria \\ Email: ayebosadoh@yahoo.com \\ Phone number: +234 8033435312}

These include the timeliness of receipt of vaccines, the coverage of the vaccine and measurement of morbidity and mortality from the target disease. For hepatitis $B$ vaccine the prevalence of acute hepatitis [5] complications such as hepatitis B associated membranous nephropathy,[6] HBsAg carrier rates [7,8] as well as prevalence of hepatocellular carcinoma[7] have been used to assess the success of hepatitits B immunization programme in various countries.

Many countries have recorded reductions in prevalence of $\mathrm{HBsAg}$ following the introduction of universal immunization for children. These include Italy, Taiwan and Gambia. ${ }^{5,7}$ In Nigeria routine coverage for hepatitis B has been reported [9] but few studies have evaluated $\mathrm{HBs} \mathrm{Ag}$ carrier rates since the introduction of hepatitis B immunization. Such studies are necessary to determine the effectiveness of the programme and to identify problems. Such problem identification is important in the development of targeted interventions for improvement of the programme. In one such study on children in rural Nigeria that evaluated 5-7 years post vaccination efficacy of hepatitis $B$ vaccine, a significantly lower HBsAg carrier rate ( $2 \%$ ) was found in immunized children compared to unvaccinated children (12\%).[10] This study was however carried out in the context of a project and protocols would have been strictly adhered to. Also the study only evaluated a narrow age range. 
A previous study in Benin City the study locale (20years ago and before the introduction of infant immunization for hepatitis B) reported a prevalence of $10.8 \%$.[11] There has been no prevalence study since that study. This study therefore set out to determine the prevalence of $\mathrm{HBsAg}$, and the hepatitis $\mathrm{B}$ vaccination status in children aged 2 months to 15 years admitted to the children's emergency room (CHER) of the University of Benin Teaching Hospital, Benin City.

\section{Methodology}

This descriptive cross-sectional study was carried out at the CHER of the University of Benin Teaching Hospital (UBTH) between February and April 2011 in Edo state of Nigeria. The UBTH is a tertiary health care facility which serves Edo state and receives referrals from its neighbouring five states. Ethical clearance for the study was obtained from the UBTH ethical review committee. Verbal consent was obtained from parents of subjects after the objectives and procedure of the study had been explained to them. Assent was obtained from children older than 10 years.

The sample size was calculated using the formula:

$$
\mathrm{n}=\frac{\underline{\mathrm{z}}^{2} \mathrm{pq}}{\mathrm{d}^{2}}
$$

where

$\mathrm{n}=$ the desired sample size

$\mathrm{z}=$ the standard normal deviate set at 1.96 which corresponds to $95 \%$ confidence interval $\mathrm{p}=$ the proportion in the target population estimated to be positive for the hepatitis B surface antigen (estimated to be 10.8\% using the prevalence found in an earlier study in Benin City)[11]

$\mathrm{q}=1.0-\mathrm{p}$

$\mathrm{d}=$ degree of accuracy desired which is 0.05

This gave a sample size of 148.03 which was approximated to 150

All children aged between 2 months and 15 years admitted to CHER and whose parents gave consent were consecutively recruited. Children who were known to have Sickle Cell Anaemia.were excluded from the study. These children were excluded because most of those that attend the CHER also attend the Sickle cell clinic of the hospital which has a comprehensive package of care for these children, This package includes ensuring that the children receive hepatitis $B$ vaccination thus coverage for the hepatitis B vaccination may be different from that of the general population of children.

Information on bio data such as age, sex, maternal and paternal educational level and occupation was obtained using a proforma. The proforma was pretested at the Institute of Child Health Immunization clinic. The instrument was researcher administered. Immunization history was obtained for each child and parents were asked to bring immunization cards, from which actual dates of receipt of various doses of the vaccine was obtained. In those who did not immediately have their immunization cards, parents were encouraged to bring same while the patients were visited daily until discharge to see if parents would comply so that the actual dates of receipt of vaccine could be ascertained. Immunization could not be verified for children whose parents could not bring their immunization cards.

Socioeconomic status was determined for each child using the educational level and occupation of both parents as described by Oyedeji et al.[12]

Five (5) mls of blood was then obtained through venepuncture under sterile conditions. The blood was spun and serum separated and then stored at $-20^{\circ} \mathrm{C}$ until the time of testing. The serum was thawed at room temperature and $\mathrm{HBsAg}$ was assayed for in the serum. The HBsAg was assayed for using DRG Enzyme linked immunosorbent assay kit by DRG International, inc. USA. The sensitivity of the assay kit was 99\%. To assess the precision and validity of the assay kits, three different levels of controls were subjected to intra and inter assay performance and this gave a mean percentage coefficient of variation of $5 \%$.

\section{Data Analysis}

Data was entered into a Statistical Package for Social Sciences (SPSS) version 13, spreadsheet. Analysis was done using the same soft ware and Graphpad Instat 3. Continuous variables were presented as means (SD) and comparisons were done using Student $t$ test. The presence of HBsAg was reported as simple percentages. Association of independent variables such as age, gender, socioeconomic status and immunization status with serostatus (the dependent variable) was tested using Chi Square test and Fishers Exact test as appropriate. Level of significance for all tests was set at $\mathrm{p}<0.05$ at $95 \%$ confidence interval.

Those in socioeconomic classes I-III were classified as high socioeconomic class while those in classes IV and $\mathrm{V}$ were classified as low socioeconomic class 
The socio-demographic characteristics of the one table I.

Table I Socio-demographic characteristics of 150 children and their parents

\begin{tabular}{|c|c|c|c|}
\hline Characteristic & $\mathbf{n}$ & $(\%)$ & Mean (SD) \\
\hline \multicolumn{4}{|l|}{ Gender } \\
\hline Male & 84 & 56.0 & - \\
\hline Female & 66 & 44.0 & - \\
\hline \multicolumn{4}{|l|}{ Age group } \\
\hline$<1$ year & 53 & 35.3 & - \\
\hline 1-4years & 71 & 47.3 & - \\
\hline 5-9years & 18 & 12.0 & - \\
\hline$\geq 10$ years & 8 & 5.3 & - \\
\hline \multicolumn{4}{|l|}{ Maternal Age } \\
\hline$\leq 24$ & 11 & 7.5 & - \\
\hline $25-29$ & 48 & 32.9 & - \\
\hline $30-34$ & 39 & 26.7 & - \\
\hline $35-39$ & 31 & 21.2 & - \\
\hline $40-44$ & 12 & 8.2 & - \\
\hline$\geq 45$ & 5 & 3.4 & - \\
\hline \multicolumn{4}{|l|}{ Mean Age } \\
\hline Children (in months) & 150 & 100.0 & $33.0(39.1)$ \\
\hline Mothers (in years) & 146 & 97.3 & $31.9(5.9)$ \\
\hline Fathers (in years) & 136 & 90.7 & $38.9(7.2)$ \\
\hline \multicolumn{4}{|l|}{ Maternal LOE } \\
\hline I & 59 & 39.9 & \\
\hline 11 & 9 & 6.1 & \\
\hline 111 & 35 & 23.6 & \\
\hline IV & 41 & 27.7 & \\
\hline $\mathrm{V}$ & 4 & 2.7 & \\
\hline \multicolumn{4}{|c|}{ Socioeconomic Status } \\
\hline High & 98 & 72.6 & \\
\hline Low & 37 & 27.4 & \\
\hline
\end{tabular}

I-university degree or equivalent, II- School certificate(Ordinary level GCE) plus teaching or other professional training III- School certificate or grade II teachers' certificate or equivalents IV- modern three, primary six certificate V- Did not complete primary school,illiterate LOE - Level of education

\section{Figure 1 Hepatitis B immunization status of study population}

age appropriately immunized $\mathbf{\square}$ incompletely immunized $\mathbf{\square}$ no immunization

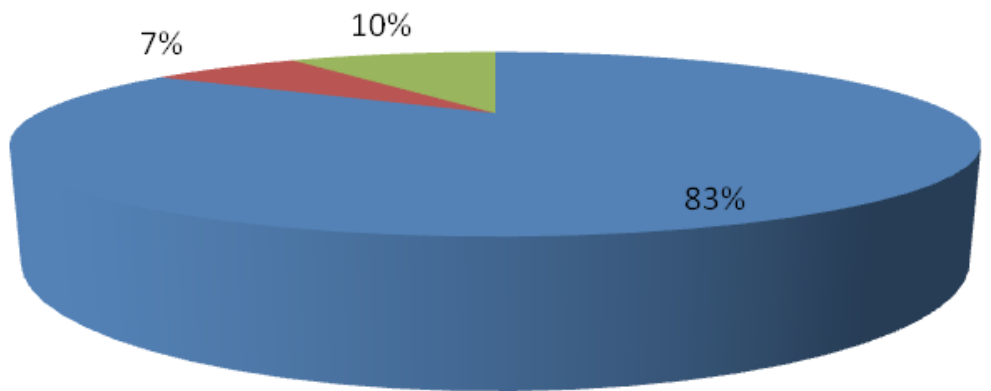


Figure 1 shows the hepatitis B immunization status of the 146(97.3\%) children for whom information on immunization was available. Immunization card was available for $41(27.3 \%)$ children. Only these 41 were analysed for age at receipt of the various doses of the hepatitis $B$ vaccine. The mean age at receipt of Hep B birth 28.3 \pm 20.4 days was significantly delayed $(p<0.0001)$.The mean age at receipt of Hep B 2 $65.9 \pm 22.8$ days was significantly different $\mathrm{p}<0.0001$ from the recommended age 42days (6weeks). The mean age at receipt of Hep B $3110 \pm 18.6$ days was also significantly delayed $\mathrm{p}<0.0002$ compared to the recommended age of 98 days (14weeks).

.The mean age (SD) at commencement of immunization (age at receipt of BCG, OPV0 and HepB Birth) was 13.5(18.4) days for BCG, 9.0(12.4) days for OPV0 and 28.3(20.4) days for Hep B Birth. The age at receipt of the different vaccines recommended for receipt at birth is shown in table 2 .

Table 2 Age at receipt of first immunizations (BCG, OPV0 and Hep B birth)

\begin{tabular}{lrrrrrr}
\hline Age at commencement of & \multicolumn{2}{c}{ BCG } & \multicolumn{3}{c}{ OPV0 } & \multicolumn{2}{c}{ Hep B birth } \\
Immunization (in days) & $\mathrm{n}$ & $\%$ & $\mathrm{n}$ & $\%$ & $\mathrm{n}$ & $\%$ \\
\hline $0-7$ & 24 & 58.5 & 25 & 71.4 & 13 & 31.7 \\
$8-14$ & 8 & 19.5 & 6 & 17.1 & 3 & 7.3 \\
$15-28$ & 3 & 7.3 & 1 & 2.9 & 2 & 4.9 \\
$>28$ & 6 & 14.7 & 3 & 8.6 & 23 & 56.1 \\
Total & 41 & 100.0 & 35 & 100.0 & 41 & 100.0 \\
\hline
\end{tabular}

Table 3 Relationship between age, gender and socioeconomic status of the studied children and their hepatitis B surface antigen status

\begin{tabular}{|c|c|c|c|c|c|}
\hline \multirow[t]{3}{*}{ Variable } & \multicolumn{4}{|c|}{ HBsAg serostatus } & \multirow{3}{*}{$*_{\mathrm{p} \text {-value }}$} \\
\hline & \multicolumn{2}{|c|}{ Positive } & \multicolumn{2}{|c|}{ Negative } & \\
\hline & $\mathrm{n}$ & $\%$ & $\mathrm{n}$ & $\%$ & \\
\hline \multicolumn{6}{|l|}{ Age } \\
\hline$<12$ months & 10 & 18.9 & 43 & 81.1 & \\
\hline$>12$ months & 11 & 19.6 & 86 & 80.4 & 0.23 \\
\hline Total & 21 & & 129 & & \\
\hline \multicolumn{6}{|l|}{ Sex } \\
\hline Male & 12 & 14.3 & 72 & 85.7 & \\
\hline Female & 9 & 13.6 & 57 & 86.4 & 1.00 \\
\hline Total & 21 & & 129 & & \\
\hline \multicolumn{6}{|c|}{ Socioeconomic status } \\
\hline High & 15 & 15.3 & 83 & 84.5 & \\
\hline Low & 6 & 16.2 & 31 & 83.8 & 1.00 \\
\hline †Total & 21 & & 114 & & \\
\hline
\end{tabular}

* Fisher's Exact Test

†Socioeconomic status could only be determined for 135 children 
Of the 150 children studied 21(13.9\%) were positive for HBsAg. Table 3 shows the relationship between the age, gender and socioeconomic status of the children and their $\mathrm{HBsAg}$ status. Of the children aged below one year $10(18.9 \%)$ were positive for $\mathrm{HBsAg}$ while $10(14.1 \%)$ of those aged between 1 and 5 years were positive and only $1(12.5 \%)$ of those aged $\geq 10$ years was positive. The association between age and $\mathrm{HBsAg}$ status was not significant $\mathrm{p}=0.23$. There were $12(14.2 \%)$ males who were positive for HBsAg. This was not significantly different from $8(13.6 \%)$ females who were positive for $\mathrm{HBsAg} \mathrm{p}>0.05$. Of the 98 children from high socioeconomic families $15(15.3 \%)$ were $\mathrm{HBsAg}$ positive and this was not significantly different from the $6(16.2 \%)$ of 37 from low socioeconomic families.

Table 4 shows the relationship between hepatitis $B$ immunization status and hepatitis B seropositivity. The seropositivity $15.4 \%$ among those who were fully immunized was not significantly different from 10.3\% among those who had incomplete/ no hepatitis B immunization. $\mathrm{p}=0.77$

Table 4 Relationship between hepatitis B immunization status and Hepatitis B serostatus

\begin{tabular}{lccccc}
\hline Immunization status & \multicolumn{3}{c}{ HBsAg Serostatus } & & \multirow{2}{*}{ *pvalue } \\
& Positive & \multicolumn{2}{c}{ Negative } & \\
& $\mathbf{n}$ & $\mathbf{0}$ & $\mathbf{n}$ & $\mathbf{\%}$ & \\
\hline Fully immunized & 18 & 15.4 & 99 & 84.6 & \\
Incomplete/ no immunization & 3 & 10.3 & 26 & 89.7 & 0.77 \\
Total & 21 & & 125 & & \\
\hline
\end{tabular}

*Fisher's Exact Test

\section{Discussion}

This study has examined various aspects of the hepatitis B immunization programme. The HBsAg seroprevalence remains high even though most of the children were said to be vaccinated. The HBsAg sero-prevalence is comparable to the findings of an earlier study[11] suggesting that there may have been no change even with the introduction of immunization programme. On the other hand it is possible that HBsAg may have been higher in the earlier study period. The possible explanation for this being that the higher sensitivity of the third generation Elisa test used in this study compared to that used in the earlier study may have accounted for the seemingly higher prevalence in this study. In a recent review of hepatitis $B$ in Nigeria, this reason was proffered as explanation for the observed higher prevalence in the more recent studies compared to older studies.[13] It is also pertinent to note that the earlier study had excluded all subjects with possible risk factors and may thus have compared to this study underestimated the overall prevalence of hepatitis B surface antigen among children admitted to the children's emergency room.

There was no significant difference in $\mathrm{HBsAg}$ seropositivity between vaccinated and incompletely/ unvaccinated children. This may have been due to few numbers of the unvaccinated and also the fact that those who were incompletely vaccinated and those who had received no immunization were grouped together for the analysis thereby possibly confounding the results. This is because it has been shown that there is some antibody response even following a single dose of the vaccine.[14,15] Also immunization in majority of the children was not validated due to non availability of their immunization cards. It is thus possible that some of those who claimed to be completely immunized may not have been immunized at all or were incompletely immunized.

The timeliness of receipt of the various doses was also examined. The marked delay in receipt of the birth doses may connote ineffectiveness of the programme in preventing perinatal transmission. The late commencement of hepatitis B immunization also meant that there would be delay in completing the schedule as was observed in this study. This means that such infants remained vulnerable for longer than usual and may indeed have acquired the virus during such extended periods of vulnerability. The lack of timelines in receipt of birth doses and completion of the schedule may have contributed to the observed lack of effect of the immunization programme on seroprevalence. In programmes that have been successful timeliness of receipt of birth doses was high.[16]

This study found age not to be significantly associated with hepatitis B status. This was in keeping with a study from Illorin.[17]Although age was not significantly 
associated with hepatitis B in this study, most of the infected children were under the age of five. In fact only one child older than 10 years was positive. This supports the fact that infections are acquired in childhood. Infections acquired in childhood are more likely to become chronic thus it is recommended that the infected children be followed up.

These findings are however different from those of previous studies which had shown higher prevalence among school age children.[18] In those studies it was opined that in sub-Saharan Africa, perinatal infections are few with rates of infection increasing with increasing age reaching a peak during school years (reflecting horizontal transmission from child to child),[18] The findings in this study may suggest a change in epidemiology with children acquiring the infection earlier in childhood. This explanation is plausible as more children are leaving home at a younger age to attend day-care and pre- school facilities.

Since older children and adolescents did not benefit from immunization against hepatitis B in infancy it would be expected that they would have had a higher prevalence. Perhaps the fewer numbers of children aged above five years in this study may be responsible for a low relative contribution to the HBsAg seropositivity in this study. These older children who were unimmunized are likely to be at continued risk for hepatitis B infection. Catchup immunization may be recommended for this group of children

The findings of this study are at variance with other studies on the impact of hepatitis B vaccination on the prevalence of hepatitis B. Studies from Gambia, Taiwan and Italy have shown that the prevalence of hepatitis B reduced following the introduction of universal infant immunization $[5,7,8]$ In these countries the coverage for the vaccine was high[19] unlike what is observed at population level in Nigeria[9] The coverage for the third dose of hepatitis B vaccine in Nigeria is $27.6 \%[9]$ Thus even though majority of the children studied were said to be immunized this may be at variance with general coverage in the population. This may then mean that population-level protection is not high contributing to a lack of observed effectiveness of hepatitis B immunization in this study.

A limitation of this study is that it is a single centre study. The fact however that the centre is a referral centre means that children from the diverse geographic areas served by the centre are represented thus making the findings more generalizable. The study is also limited by the inability to verify the immunization status of most of the children.
In conclusion, in view of the high prevalence of HBsAg in the studied children efforts at increasing the effectiveness of the immunization programme should be made especially improving the timeliness of receipt of birth doses which was delayed in this study.

\section{Conflict of interest: None declared}

\section{Author contribution}

AES conceptualized the study, was involved in data collection, analysis and interpretation, wrote the initial draft and approved the final draft

AO contributed to the concept, was involved in data analysis and interpretation and approved the final draft.

\section{References}

1. World Health Organization. Introduction of hepatitis $B$ vaccine into childhood immunization services. Management guidelines, including information for health workers and parents. WHO/V\&B/01.31 2001

2. World Health Organization. Hepatitis B fact sheet no 204. Available at: http://www.who.int/mediacentre/ factsheets/fs204/en Accessed 16th January 2012

3. Federal Ministry of Health, Lagos, Nigeria. National Immunization policy and standard of practice 1995

4. World Health Organization. Vaccine preventable disease monitoring system, 2005 global summary immunization profile - Nigeria. Available at: http://www.who.int/vaccines/global summary/ immunization/countryprofileresult.cfm. Last accessed 22nd April 2009

5. Gervais A, Longuet P, Leport C. A success story: universal vaccination in Italy - what has to be done to eradicate acute hepatitis B? Clin Infect Dis 2008; 46:876-7

6. Bhima R, Coovadia AM, Adhikari M, Connoly CA. The impact of the hepatitis $\mathrm{B}$ virus vaccine on the incidence of hepatitis B virus associated membranous nephropathy. Arch Pediatr Adolesc Med 2003;157:102530

7. Ni YH, Chen DS. Hepatitis B vaccination in children: The Taiwan experience Pathol Biol 2009;58:296-300

8. Whittle H, JaffarS, Wansbrough M, Mendy M, Dumpis U, Collinson A et al.. Observational study of vaccine efficacy 14years after trial of hepatitis $B$ vaccination in Gambian children BMJ 2002;325:569

9. National Bureau of Statistics (NBS) 2011, Nigeria Multiple Indicator Cluster Survey 2011. Final Report, Abuja, Nigeria. Available at

http://www.nigerianstat.gov.ng/ext/latest_release/ MICS4\%20Report.pdf Last accessed 13 ${ }^{\text {th }}$ February 2012 
10. Odusanya OO, Alufohai E, Meurice FP, Ahonkhai VI. Five-year post-vaccination efficacy of hepatitis $\mathrm{B}$ vaccine in rural Nigeria. Human Vaccines 2011;76:625-9

11. Abiodun PO, Okolo SN. HBS-Antigenaemia in Inand Outpatient children at University of Benin Teaching Hospital. Nig J Paed 1991;3:107-13

12. Oyedeji GA. Socioeconomic and cultural background of hospitalised children in Ilesha. Nig J Paed 1985;12:111-17

13. Emechebe GO, Emodi IJ, Ikefuna AN, Ilechukwu GC, Igwe WC, Ejiofor OS et al. Hepatitis B virus infection in Nigeria - a review. Niger Med J 2009;50:1822

14. Halperin SA, Dobson S, McNeil S, Langley JM, Smith B, McCall-Sani $\mathrm{R}$ et al. Comparison of the safety and immunogenicity of hepatitis $B$ virus surface antigen co-administered with an immunostimulatory phosphorothioateoligonucleotideandalicensedhepatitis $B$ vaccine in healthy adults. Vaccine 2006;24:20-6 15. Cassidy WM, Watson B, Ioli VA, Williams K, Bird S,
West DJ. A randomized trial of alternative two- and threedose hepatitis $B$ vaccination regimens in adolescents: antibody responses, safety and immunologic memory. Pediatrics 2001;47:626-31

16. Smith EA, Jacques-Carrol L, Walker TY, Sirotkin B, Murphy TV. The national perinatal hepatitis B prevention program 1994-2008. Pediatrics 2012 DOI:10.1542/ peds.2011-2866. Available at http://pediatrics. aappublications.org/content/early/2012/03/21/ peds.2011-2866

17. Agbede OO, Iseniyi JO, Kolawole MO, Ojuawo A. Risk factors and seroprevalence of hepatitis B surface antigenaemia in mothers and their preschool age children in Ilorin, Nigeria. Therapy 2007;4:67-72

18. Chukwuka JO, Ezechukwu CC, Egbuonu I, Okoli CC. Prevalence of hepatitis B surface antigen in primary school children in Nnewi, Nigeria. Nig J Clin Pract 2004;7:8-10

19. Shepard CW, Simard EP, Finelli L, Fiore AE, Bell BP. Hepatitis B virus infection; Epidemiology and vaccination. Epidemiol Rev 2006;28:112-25 